\title{
AOR
}

Selected Papers of \#AolR2020:

The $21^{\text {st }}$ Annual Conference of the Association of Internet Researchers

Virtual Event / 27-31 October 2020

\section{MOVE, EAT, SLEEP, REPEAT: RHYTHMIC STRUGGLES IN PROACTIVE SELF-TRACKING PRACTICES}

\author{
Harley Bergroth \\ University of Turku \\ Minna Saariketo \\ Stockholm University
}

Proactive self-tracking is a proliferating digital media practice that involves the gathering data about the body and one's everyday patterns of being outside the context of clinical health care. Common consumer-grade gadgets for self-monitoring track for example steps, heart rate, calorie consumption, and various biomarkers related to the quality of one's sleep (Lupton, 2016; Schüll, 2016). Many studies have noted that self-tracking technologies affect people's everyday modes of thought and action, and 'stick' to their lifeworlds as these technologies seek to promote 'improved' and healthier modes of behavior (Schüll,2016; Fotopoulou \& O'Riordan, 2017; Bergroth \& Vuorinen, 2019). While people may readily explicate resistance towards the demanding, optimizationrelated character of self-tracking devices, these technologies still resonate in the 'technological unconscious' (Thrift \& French, 2002) as self-tracking technologies tap in to the habitual and affective dimensions of human experience.

In the paper, we address the gap that still exists in exploring the mechanisms by and through which these human-technology attachments operate in practice. We focus on the rhythmic aspects of self-tracking by asking how specific self-tracking devices and interfaces attract and prescribe repetition, rhythms, beats, pulses, and cycles into everyday lives. In so doing, we elaborate how different systems - namely human bodies and technical systems of self-tracking - interact rhythmically. While self-tracking may present harmonious sequences of human-technology co-operation, for the purposes of this paper, we will focus on the diverse layers of struggle in self-tracking practices, including for example falling out of rhythms, longing for rhythms, being unable to understand or follow certain rhythms, or unwillingness to adhere to specific rhythms.

Suggested Citation (APA): Bergroth, H. \& Saariketo, M. (2020, October 27-31). Move, eat, sleep, repeat: Rhythmic struggles in proactive self-tracking practices. Paper presented at AolR 2020: The $21^{\text {st }}$ Annual Conference of the Association of Internet Researchers. Virtual Event : AolR. Retrieved from http://spir.aoir.org. 
Theoretically we draw from new materialist ontology and the idea of self-tracking agencements and combine it with Henri Lefebvre's (1992/2004) rhythmanalysis. In the analysis, we have traced, following Lefebvre's conceptualization, the formation of eurhytmia (harmony of rhythms), arrhythmia (discordance), and polyrhythmia (multiplicity of overlapping rhythms). Our contribution to the rhythmanalytic theory is complementing it with theorization on the hierarchical organisation of rhythms. In relation to human-technology attachments and power, we consider self-tracking practices as agencements of 'dressage' (ibid: 40-44), referring to how self-tracking seeks an 'automatism of repetitions' that always includes also disruptions, crises or struggles in the system; crises that have 'origins in and effects on the rhythms' themselves.

Methodologically we are inspired by Lefebvre's idea that people live in rhythms and their bodies are crucial node in the rhythmic fabric of life and society. For Lefebvre, rhythms are corporeal; to grasp a rhythm it is necessary to have been grasped by it (Lefebvre, 1992/2004: 27). Inspired by this, we applied the method of 'collaborative autoethnography' (e.g. Chang, Hernandez \& Ngunjiri, 2012). Through the process of tracing the rhythmicities created in/with activity trackers, we engaged both authors' personal and situated fieldwork experiences of wearing self-tracking devices, while simultaneously cross-analyzing, comparing, and contrasting our experiences and our visual-textual research materials. Both authors used activity trackers (FitBit Charge HR and Garmin VivoSmart HR+, and later Apple Watch S3), in total 25 months between April 2015 and December 2019. We kept a diary of our observations, photographed the screens of the devices, and took screenshots from the smartphone apps. The observations and experiences were regularly reflected both face-to-face and via instant messaging, and this interaction constitutes a crucial part of our research data.

Instead of following the mainstream of collaborative autoethnographic research and focusing in perspectives on or experiences of issues that relate to personal or professional identities or the self, we placed technology at the centre of our study. We relate to the method of ethnographic research that 'has technology as its perspective' called 'technography' (Bucher, 2012). Thus, our methodology is built on technographical collaborative autoethnography.

Our findings illustrate the multiplicity of rhythms and rhythmic struggles with everyday networked technology. In the analysis, we describe how the self-tracking devices have educated us on a certain type of wellbeing and self-care, while also ritualizing wellbeing by organizing time in new ways and seeking to establish automatism in self-care. Our observations shed light on the ways in which the technologies bent us into new rhythms. Simultaneously, we have shared an uncomfortable surprise of the sneaky habitualisation that has happened despite our critical analytical starting point discussed in the paper through the concept of dressage. A main example of this is the pleasure and attachment that one of us feels in using Apple Watch despite the initial rejection and resentment to the smartphone extension vibrating in the wrist that made her constantly aware of the highspeed and persuasive rhythms of the digital world. 
In the analysis, we discuss the temporal struggles of fitting time and attention seeking self-tracking devices into the everyday. We reflect how devices require effort in initiating the use, adjusting the default settings, entering one's details, becoming familiar with the different functions, and learning to interpret the visualisations. Second, the materiality of device organizes the user's everyday in unexpected ways: the need to recharge the battery forces the user to choose what data to give up or to synchronize the recharge and daily movements so that no data is lost. These reflections on 'letting data go' shed light the persuasive power of constant data collection and adjusting the user to its logics. Third, we argue that feeling haptically the constant flow of notifications while using activity trackers that are extensions to a smartphone, can be a moment of becoming conscious of the rhythm of manifold persuasions that a user is digitally targeted with.

To conclude, the analysis has given us a chance to closely analyze the rhythms and beats that we interpret as illustrations of the 'technological unconscious' (Thrift \& French 2002). We bring our observations in dialogue with the contemporary critical arguments pointing to the design of products that are made as addictive as possible in the race for 'hijacking minds' and capturing attention (see e.g. Lewis, 2017; Thompson, 2017). Our research contributes empirically to the lack of research that has systematically examined these seductive and yet controlling properties of software.

Bergroth, H. \& Vuorinen, J. (2019) Towards the Ontology of Becoming in Self-tracking Research. In: Kurosu, M. (ed.) Human-Computer Interaction. Perspectives on Design. HCII 2019. Lecture Notes in Computer Science, vol 11566. Springer, Cham. pp 270287.

Bucher, T. (2012) Programmed sociality: A software studies perspective on social networking sites. Ph.D. diss.

Chang, H., Hernandez, K.-A. C., \& Ngunjiri, F. W. (2012). A Collaborative Autoethnography. Walnut Creek: Left Coast Press.

Cifor, M. \& Garcia, P. (2019). Inscribing Gender: A Duoethnographic Examination of Gendered Values and Practices in Fitness Tracker Design. In Proceedings of the 52nd Hawaii International Conference on System Sciences. Scholar Space, Honolulu, HI, USA, 2132- 2141. http://hdl.handle.net/10125/59652

Fotopoulou, A., \& O’Riordan, K. (2017). Training to self-care: Fitness tracking, biopedagogy and the healthy consumer. Health Sociology Review, 26(1): 54 - 68.

Lefebvre, H. (1992/2004) Rhythmanalysis. Space, time and everyday life. London \& New York: Continuum.

Lewis, P. (2017). 'Our minds can be hijacked': The tech insiders who fear a smartphone dystopia. The Guardian, October 6, 2017.

https://www.theguardian.com/technology/2017/oct/05/smartphone-addiction-siliconvalley-dystopia?CMP=share_btn_fb( 
Lupton, D. (2016) The Quantified Self: A Sociology of Self-Tracking. Cambridge: Polity Press.

Schüll, N.D. (2016) Data for Life: Wearable Technology and the design of self-care. BioSocieties. Online First: 1-17.

Thompson, N. (2017) Our minds have been hijacked by our phones. Tristan Harris wants to rescue them. Wired 26.7.2017. https://www.wired.com/story/our-minds-havebeen-hijacked-by-our-phones-tristan-harris-wants-to-rescue-them/(accessed 4.11.2017).

Thrift, N. \& French, S. (2002) The automatic production of space. Transactions of the Institute of British Geographers, 27(3): 309-335. 